\title{
Protection of personal data at the level of economic structures within companies in Romania
}

\author{
Monica Florentina CALOPEREANU \\ The Bucharest University of Economic Studies, Bucharest, Romania \\ monica.calopereanu@gmail.com \\ Alin Nicușor CALOPEREANU \\ The Bucharest University of Economic Studies, Bucharest, Romania \\ alin.calopereanu@gmail.com \\ Daniela Nicoleta SAHLIAN \\ The Bucharest University of Economic Studies, Bucharest, Romania; \\ daniela.sahlian@cig.ase.ro \\ Adriana Florina POPA \\ The Bucharest University of Economic Studies, Bucharest, Romania; \\ adriana.popa@cig.ase.ro \\ Marian ȘUICĂ \\ Technical University of Civil Engineering of Bucharest, Bucharest, Romania \\ mariansuica@gmail.com
}

\begin{abstract}
The accounting profession must comply with the provisions of the Regulation no. 679 of 27 April 2016 on the protection of individuals with regard to the processing of personal data and on the free movement of such data and repealing Directive 95/46 ("GDPR"). GDPR requires companies to take mandatory technical and organizational measures to demonstrate that personal data has been secured. Accounting practitioners process personal data and are therefore required to comply with specific legislation in the field of personal data protection. Professionals accountants are directly affected by these provisions as they collect, store and process personal data relating to customers, employees and subcontractors. This article aims to identify the risks and implications that can appear from the application of the GDPR at the level of the economic departments of the companies operating in Romania
\end{abstract}

Keywords: GDPR, Economics, Accounting, Data Protection, Compliance with Regulation (EU) 679/2016, Privacy.

\section{Introduction}

In the European Union, the right to the protection of personal data, and the right to privacy, are considered fundamental human rights. Unlike the European Union, The United States of America is notable for not having adopted a comprehensive information privacy law, but rather having adopted limited sectoral laws in some areas ("Information privacy law," 2019).

In the European Union, for all bodies (legal persons) and for those who offer goods and services on the territory of the European Union or to citizens of the European Union, the interpretation and implementation of the legal rules on the protection of personal data has 
become mandatory from 27 April 2016, the day on which the Regulation (EU) 2016/679 was adopted.

In this context, in which personal data of individuals are collected and processed in companies and institutions from European Union, awareness of individuals is a core element in the big data era and the data-driven economy: it is the optimal balancing between fostering innovation (through the free flow of data) and protecting individuals' human rights (Malgieri \& Custers, 2018).

Regulation (EU) 2016/679 of the European Parliament and of the Council of 27 April 2016 on the protection of individuals with regard to the processing of personal data and on the free movement of persons of these data and repealing Directive 95/46 / EC (General Data Protection Regulation), was published in the Official Journal of the European Union, series L $119 / 1$.

There were some important reasons for adoption of this Regulation:

- The principles relating to the protection of individuals with regard to the processing of their personal data should respect their fundamental rights and freedoms, regardless of the nationality or place of residence of natural persons;

- The Regulation seeks to contribute to achieving an area of freedom, security and justice, to economic and social progress, to the consolidation and convergence of economies within the internal market and to the welfare of individuals;

- Protection of the right to family, private and private life in the processing of personal data.

\section{Literature review}

In European Union, GDPR is now, the unique European legal framework for personal data protection and the new rules affect all service providers, including accounting firms or economic departments of any entity.

The GDPR expands the scope of data protection so that anyone or any organization that collects and processes information related to EU citizens must comply with it, no matter where they are based or where the data is stored (Tankard, 2016).

The current challenges related to personal data protection, that GDPR aims to meet will strengthen online privacy rights and boost Europe's digital economy (Tikkinen-Piri et al., 2018) and economy in general in European Union.

At the beginning of this article, we will present in this article certain terms from the Regulation (EU) 2016/679, terms that may be incomprehensible and require a multidisciplinary approach.

In Regulation (EU) 2016/679, at "Article 4: Definitions": "personal data" means any information relating to an identified or identifiable natural person ("the data subject"). That is, "an identifiable natural person is a person who can be identified, directly or indirectly, in particular by reference to an identifier, such as a name, an identification number, location data, an online identifier, or one or more specific elements, of its physical, physiological, genetic, psychological, economic, cultural or social identity. "(European Parliament, 2016)

"Data processing means any operation or set of operations performed on personal data or on personal data sets with or without the use of automated means such as collecting, recording, organizing, structuring, storing, adapting or modifying, extracting, consultation, use, 
disclosure by transmission, dissemination or otherwise making available, alignment or combination, restriction, erasure or destruction".(European Parliament, 2016)

Article 6 - Paragraph 1 clearly specifies that "Processing is legal only if and to the extent that at least one of the following conditions applies"(European Parliament, 2016):

consent - the data subject has consented to the processing of his or her personal data for one or more specific purposes;

PICBE $\mid 615$

contract - processing is required to execute a contract to which the data subject is a party or to take steps at the request of the data subject prior to the conclusion of a contract;

legal obligation - processing is necessary in order to fulfill a legal obligation incumbent upon the operator;

vital interests - processing is necessary to protect the vital interests of the person concerned or of another individual;

public interest - processing is necessary for the performance of a task which is in the public interest or which results from the exercise of the public authority with which the operator is invested;

legitimate interests - processing is necessary for the legitimate interests pursued by the operator or a third party, unless the interests or fundamental rights and freedoms of the data subject that require the protection of personal data are prevalent, in particular where the person target is a child.

The rights of individuals set forth in the Regulation (EU) 2016/679 as regards the processing of personal data:

- Right of access to processed personal data: the right to obtain a confirmation that your personal data are processed or not, and, if so, access to the personal data type and the conditions of its processing by the wording an application to that effect to the operator;

- The right to request the rectification or deletion of personal data: the possibility to request, by sending a request in this respect to the operator, the rectification of personal data that is inaccurate, the supplementation of the personal data, if they are incomplete or deletion of personal data in situations where:

- Personal data is no longer required for its original purpose (and there is no new legal purpose for processing)

- The legal basis for the processing is the consent of the data subject and the data subject withdraws his / her consent and there is no other legal basis for processing

- The data subject exercises his right to object and the operator has no reason to continue the processing that prevails

- Personal data has been processed illegally

- Deletion is required to comply with EU or Romanian law

- Personal data has been collected in connection with the provision of information society services provided to children (where applicable) for which consent is governed by special rules;

- Right to request restriction of processing: the right to obtain restriction of processing in situations where:

- Consider inaccurate personal data to be processed for a period that allows the operator to verify the accuracy of personal data;

- Processing is illegal, but it is not desirable to delete personal data, requiring only restriction of their use; 
- If the operator no longer requires personal data for processing for the purposes mentioned above but requires data for the establishment, exercise or defense of a right in court;

- The data subject opposed to the processing for the period of time to verify that the legitimate grounds of the controller prevail over the rights of the data subject.

- The right to withdraw consent for processing where the processing is based on consent without affecting the lawfulness of the processing carried out until the moment of withdrawal of the consent;

- The right to object to the processing of personal data on grounds relating to the particular situation where the processing is based on a legitimate interest and at any time the processing of personal data for direct marketing purposes, profiles;

- The right not to be the subject of a decision based solely on automated processing, including the creation of profiles, which produces legal effects which affect the data subject or similarly affect it to a significant extent;

- The right to data portability, that is, the right to receive personal data that has been provided to the operator in a structured, commonly used and readable form, and the right to transmit such data to another operator, where the processing is based on consent or execution of a contract and is carried out by automatic means;

- The right to lodge a complaint with the National Supervisory Authority for Personal Data Processing and the right to appeal to the competent courts.

\section{The principles of personal data processing}

These principles are provided in Art. 5 from the Regulation (EU) 2016/679: "Principles related to the processing of personal data":

- Legality, equity and transparency - an essential principle associated with fundamental human rights. Personal data must be processed "legally, fairly and transparently to the data subject".

- Goal limitations - Personal data must be collected for well-defined, explicit and legitimate purposes, and subsequent processing must not deviate from these purposes.

- Data minimization - By this principle, operators are advised that any collection of personal data must be thoroughly analyzed before data is actually obtained, which must be most relevant and strictly limited to what is absolutely necessary for the purposes of which are processed.

- The accuracy of the information - operators must take all measures to ensure the validity of the data, and the inaccurate ones must be updated quickly or deleted.

- Storage limitation - The data should be kept as long as necessary for the assumed pelleting.

- Integrity and confidentiality - The processing of personal data must be done in its own safe conditions, including "protection against unauthorized or unlawful processing and against loss, destruction or accidental damage by taking appropriate technical or organizational measures."(European Parliament, 2016) Whoever does not respect this principle is directly exposed to security breaches and confidentiality, being a safe candidate for extremely severe penalties. 
In the GDPR (Article 5, paragraph 2), the principle of responsibility is clearly stated: "The operator must be responsible for compliance with paragraph 1 and be able to demonstrate that compliance (" responsibility ")."(European Parliament, 2016)

In other words, the most important provision of the Regulation is the principle of responsibility. GDPR asks you not only to follow the principles - for example, by documenting your decisions about a processing activity, but also to demonstrate this responsibility at any time.

Concluding, the rules established in accordance with the stated principles are contained in Recital 39 of the GDPR:

- Any processing of personal data must be legal and fair.

- The principle of transparency requires that any information and communication relating to the processing of such personal data must be easily accessible and easily understandable and that simple and clear language is used.

- Individuals should be informed of the risks, rules, guarantees and rights in the processing of personal data and how to exercise their processing rights.

- The specific purposes of processing personal data must be explicit and legitimate and determined at the time of collection of the data.

- Personal data must be appropriate, relevant and limited to what is necessary for the purposes for which it is processed.

- Personal data should only be processed if the purpose of the processing cannot reasonably be met by other means.

- The operator must set deadlines for the deletion or periodic review.

- Personal data must be processed in a way that adequately ensures security and confidentiality, including to prevent unauthorized access to or use of unauthorized personal data and equipment used for processing.

\section{Applying GDPR to an entity's economic activity.}

In the last years, there were some rapid changes in the IT technologies and in special in the storage capacity and advanced network technology. all these changes made it possible for companies to collect and process personal data efficiently and securely (Tikkinen-Piri et al., 2018).

Among the first issues to be determined when discussing the application of personal data protection rules in the context of economic activity should be to establish a role in the GDPR context.

The GDPR Regulation defines the "operator" - CONTROLLER in English - as "a natural or legal person, public authority, agency or other body which, alone or with others, determines the purposes and means of processing personal data" (Article 4 point 7).

Although in the definition is the term natural person, in the sense of the Romanian legislation it is the Authorized Physical Person (PFA), GDPR applying strictly in the relationship between a legal entity (the operator) and a natural person (the person concerned).

The responsibilities described below can be attributed to an individual (but acting on behalf of the entity) or apply to the entire organization.

\section{Responsibilities for a Data Operator}


According with Regulation (EU) 2016/679, the data operator has the following responsibilities:

- To ensure that the principles relating to the processing of personal data as described in Article 5 of the GDPR Regulation are respected and are able to demonstrate compliance;

- To ensure that, in certain cases, the consent of the data subject to the processing of personal data is obtained where necessary, including the consent of the parents for children;

- Provide all necessary information under the GDPR Regulation to the targeted person in a concise, transparent, comprehensible and easily accessible format using simple and clear language;

- Facilitate the exercise of the data subjects' rights under the GDPR Regulation and keep informed individuals informed of the progress of their application;

- Implement appropriate technical and organizational measures to ensure and be able to demonstrate that processing is carried out in accordance with the GDPR Regulation;

- To ensure that they only choose those empowered persons who provide sufficient safeguards to implement appropriate technical and organizational measures in accordance with the GDPR Regulation and at the same time ensure the protection of personal data;

- Keep a record of the personal data processing activities under the responsibility of the person empowered;

- Cooperate, on request, with the supervisory authority in the performance of its tasks;

- Ensure that any person acting under the authority of the person empowered and having access to personal data does not process them, except for the instructions of the person empowered;

- Report a violation of personal data to the supervisor, unless the breach is not likely to create a risk to the rights and freedoms of individuals in accordance with the organization's procedures;

- Document any violation of personal data, including facts relating to personal data breaches, their effects and remedial action taken;

- If necessary, notify the data subject of a personal data breach notification without undue delay;

- Perform impact assessments on data protection, as appropriate, when required;

- Designate a Data Protection Officer when required by the GDPR Regulation, publish its details and communicate it to The National Supervisory Authority For Personal Data Processing;

- Support the Data Protection Officer in the performance of his / her tasks, providing the necessary resources to carry out these tasks and access to personal data and processing operations;

- Transfer personal data to a third country or to an international organization only if the operator or person empowered has provided adequate safeguards and provided that the applicable rights of the data subjects and effective remedies for the data subjects are available.

\section{Proxy person: PROCESSOR}

GDPR defines "authorized person" as "natural or legal person, public authority, agency or other body processing personal data on behalf of the operator" (Article 4 (8)). Although in the definition is the term natural person, according to the Romanian legislation it is the 
Authorized Physical Person (PFA), GDPR applying strictly in the relationship between a legal person (the person authorized) and a natural person (the person concerned). The responsibilities described below can be attributed to an individual (acting on behalf of the organization) or apply to the entire organization.

Engaging a processor to process personal data on behalf of an organization is common place in both the private and public sectors (Pantlin et al., 2018)

The person empowered has the following responsibilities:

- Ensure that any processing of personal data is governed by a contract or other legal act that determines the object and duration of the processing, the nature and purpose of the processing, the type of personal data and the categories of data subjects and the obligations and rights of the controller data;

- Process personal data only on the basis of the documented instructions of the data controller, including the transfer of personal data to a third country or an international organization;

- Ensures that individuals authorized to process personal data are committed to maintaining confidentiality or have a legal obligation of confidentiality;

- Implement appropriate technical and organizational measures to ensure a level of security appropriate to the risk associated with unauthorized processing of personal data;

- Obtain the prior or general prior authorization of the data controller before hiring another authorized person;

- Assist the data controller in meeting the data controller's obligation to respond to claims for the rights of the data subject;

- Delete or return all personal data to the data carrier after termination of service provision;

- Provide the data controller with all the information necessary to demonstrate compliance with the obligations laid down in the GDPR Regulation and allow and contribute to audits, including inspections, conducted by the data controller or another data controller authorized by the data controller;

- Maintain a record of all categories of processing activities performed on behalf of a data operator;

- Cooperate on request with the supervisory authority in the performance of its tasks;

- Ensure that any person acting under the authority of the person empowered who has access to personal data does not process them solely on the basis of the instructions of the data controller;

- Notifying the data operator without undue delay after detecting a personal data breach;

- Designate a data protection officer when required by the GDPR Regulation, publish its details and communicate it to the supervisory authority;

- Support the Data Protection Officer in the performance of his / her tasks, providing the necessary resources to carry out these tasks and access to personal data and processing operations.

A person empowered by the operator becomes an operator if he uses personal data for purposes other than the one transmitted by the operator, or fails to comply with the operator's instructions. 
A person receiving data from the operator without performing any other processing data is the recipient.

A third party is a natural or legal person who does not act in accordance with the operator's instructions (and is not the data subject).

A third-party consignee is a person or entity legally separate from the operator, but receiving personal data from the operator.

PICBE $\mid 620$

Concluding, if the economic structure of an organism is integrated into its structure, it acts as an operator. If the service, or some of the services (accounting, marketing, etc.) are outsourced, then we speak of a person empowered by the operator.

The measures adopted by the entity's economic structure need to be harmonized with the personal data protection policies adopted at the level of the legal entity, with their adaptation to the specifics of the activity.

In the case of firms providing accounting services, we can outline a number of steps to follow, and rules to be adopted in the field of personal data.

From the beginning, we would like to point out that the overwhelming majority of tax documents also contain personal data. In addition, in practice, a large number of accounting firms also deal with Revisal, where they have access to all employees' data.

Synthetically, the contract concluded between an operator and an accounting firm provides in particular that the person empowered by the operator:

- Process personal data only on the basis of documented instructions from the operator;

- Ensure that individuals authorized to process personal data are committed to privacy or have an appropriate statutory duty of confidentiality;

- Take all measures necessary to ensure the security of data processing in accordance with Article 32;

- Comply with the conditions mentioned in paragraphs 2 and 4 of art. 28 regarding the conditions of recruitment of another person authorized by the operator;

- Taking into account the nature of the processing, provides the operator with appropriate technical and organizational measures, to the extent feasible, to fulfill the operator's obligation to respond to requests for the right of the data subject to exercise the rights provided for in Chapter III of the Regulation on the rights of the data subject such as information and access to personal data, the right to rectification and deletion of data, the right to restrict the processing or the data portability;

- Assisting the operator to ensure compliance with the obligations laid down in Articles 32 to 36, taking into account the nature of the processing and the information available to the person empowered by the operator;

- At the choice of the operator, delete or return to the controller all personal data after termination of the provision of processing-related services and remove existing copies, unless Union or national law requires the storage of personal data;

- Provide the operator with all the information necessary to demonstrate compliance with the obligations laid down in this Article, allow audits, including inspections, carried out by the operator or other designated auditor and contributing thereto. It shall immediately inform the operator if, in its opinion, an instruction violates this Regulation or other provisions of national or Union law on data protection. 


\section{Compliance steps for accounting firms}

Without claiming to have a guide to implementing the GDPR provisions, we can outline some steps that accounting firms should follow to comply with the specific privacy laws.

In terms of data collection, these are basically three in number but can be combined:

- Directly from the data subject;

- Through online identifiers (cookies, ip);

PICBE $\mid 621$

- From a third party.

If we have a different legal basis for employee data processing, ie labor law, marketing activities require the user's express consent or defining a legitimate interest of the company, processing based on it. All these aspects are related to the entire process of alignment with the GDPR and should be discussed at the point of time with those responsible for this issue.

\section{Confidentiality policy of a firm specializing in the provision of accounting consulting services.}

When any processing of personal data has to be documented and the documentation must demonstrate the need for processing, its basis, data recipients, and security measures taken, the Privacy Policy must first include company identification data processes personal data, and information from privacy policies must be:

- Concise, transparent, comprehensible, easily accessible;

- Clear and simple, especially if addressed to children;

- Made available for free to individuals.

In addition to company identification data processing personal data, the privacy policy of accounting firms should determine:

- What data collects and processes the company;

- For what purposes it collects and processes the data;

- The rights consumers have in relation to their personal data;

- Third parties who have access to these data;

- The type of data collected;

- Defining, at least minimally, appropriate technical and organizational measures that are mandatory to demonstrate that personal data has been secured.

\section{Minimizing collected data and other recommendations.}

In addition to minimum security measures, some specialists recommend that accountancy firms take additional steps, such as checking partners involved in data processing, because they also have access to customer data. Also for good compliance, it is useful to train staff on data protection so that employees know what they should do and what they do not, but also what their tasks and responsibilities are in ensuring data protection.

It is very important for companies to minimize the data collected. In the idea that for example, when issuing an invoice, the personal numeric code of the person should not be required, but only his full address, just as the series does not need and the number on the person's delegated bulletin, his name and address of residence being sufficient.

Retaining personal data in the case of economic activities of an entity.

Regarding archiving, art. 25 par. (1) of Accounting Law 82/1991 republished in the Official Gazette, Part I no. 454 from 18/06/2008 establishes that mandatory accounting records and 
the supporting documents that are the basis of the records in the financial accounts, shall be kept in the archives of the persons provided in art. 1 (commercial companies, national societies / companies, autonomous municipal companies, national research and development institutes, cooperative societies and other legal entities have the obligation to organize and manage their own accounting, respectively financial accounting, according to the present law, and management accounting adapted to activity specific) for 10 years, starting with the date of the financial year in which they were drawn up, with the exception of the wage states that are kept for 50 years. According to par. (2) of the same article, by exception may be justified, by order of the Minister of Economy and Finance, the accounting records and supporting documents kept for 5 years.

The annual financial statements are kept for 10 years, as provided by art. 35 par. (3) of the same normative act. In case of cessation of activity, the annual financial statements, as well as the registers and other documents referred to in art. 25 shall be handed over to the state archives in accordance with the legal provisions in the field.

Rules on the archiving and keeping of the registers and of the financial-accounting documents are found in the Methodological Norm for the preparation and use of financial and accounting documents approved by OMEF no. 3512/2008 regarding the financialaccounting documents as follows:

- 50. The persons referred to in art. 1 of the Law no. 82/1991, republished, have the obligation to keep in their archives the accounting registers, the other accounting documents, as well as the supporting documents that are the basis of the registration in the accounting. The keeping of registers and supporting and accounting documents is done at the tax domicile or at the secondary offices, as the case may be.

Registers and supporting and accounting documents may be archived, on the basis of service contracts, for consideration, by other Romanian legal persons having appropriate conditions. In this case, the responsibility for the archiving of the financial-accounting documents lies with the administrator, the authorizing officer or another person who has the obligation to manage the beneficiary unit.

The unit that entrusted the documents to the archive, ie the beneficiary unit, will notify the territorial tax body of this situation.

On the occasion of the checks carried out by the competent bodies, the legal entities are obliged, upon request, to submit the requested documents at the fiscal domicile. The control bodies of the Ministry of Economy and Finance may prohibit the archiving of registers, supporting documents and accounts in locations other than at the tax domicile or at the secondary offices, if they consider that they are not properly maintained.

- 51. The term of keeping the wage states is 50 years and the term of keeping the registers and of the supporting and accounting documents is 10 years from the date of closing the financial year during which they were drawn up, except for those stipulated at points 52 , 53 and 54.

-52. The invoices related to the capital goods and the immovable goods, which are the basis for the deduction of the VAT deductible for the taxable persons with mixed regime and the persons partially liable to tax in accordance with the provisions of the Fiscal Code, shall be kept according to the term stipulated in art. 149 para. (6) of the Law 571/2003 on the Fiscal Code, as subsequently amended and supplemented. 
- 53. The documents provided in Annex no. 4 can be maintained for a period of only 5 years if the unit's own needs do not require them to be retained for a longer period of time.

- 54. Financial-accounting documents attesting to the provenance of goods with a life span of more than 10 years are usually kept for a longer period of time or for the period of use of the goods.

- 55. In case of termination of the activity of the persons provided in art. 1 of the Law no. 82/1991, republished, the accounting documents are archived according to the provisions of Law no. 31/1990 regarding the commercial companies, republished, with the subsequent modifications and completions, or shall be handed over to the state archives, according to the legal provisions in the matter, as the case may be.

\section{Methodology}

In this article, we have used the qualitative methodologies that consists in the analysis of the approved official documents, Regulations and other documents regarding the evolution and development of the personal data protection field (analysis of the national and European regulations in this matter).

Comparative analyzes have been made on national and international regulations, with emphasis on the provisions of the Regulation (EU) 2016/679.

The main purpose of our methodology (qualitative methodology analysis) is to define the field of research, to analyze and to interpret specific aspects of the analyzed field of personal data protection.

Specialized papers of the specialists from this field have been used in this research and also we have used other legislative acts and documents approved in Romania and in European Union.

\section{Results and discussions}

In this complex process of protection of personal data at the level of economic structures within companies in Romania, there must be identified all the personal data that are collected and processed within those departments. In this process, the right to the data processing must be correctly identified and also, it must be idenfied and respected, the employee's rights in relation to the processing of personal data.

Regulation (EU) 2016/679 raises some obligations to protect personal data for all private or public bodies in the European Union, obligations that we have presented extensively in this article.

\section{Conclusion}

Despite the existence of many questions about whether or not to apply the provisions of the Regulation, or whether the provisions of the Regulation apply to activities carried out in a particular firm or in a particular field of activity, we must understand that the provisions of the Regulation are mandatory still in force within the Romanian companies.

From this article, taking into account all the data presented so far, it is clear that there is a need to adopt a set of internal procedures and rules for the strict application of the provisions of the Regulation, especially in the financial and accounting departments of the companies registered in Romania and in the European Union. 
The obligation to protect all the personal data collected and processed is mandatory from European Union. The subject of personal data protection is extremely wide, the absence of explicit rules of application being the engine of endless discussions in the interpretation of some articles of the Regulation. We can identify and implement our own personal data protection system, as long as we respect the provisions of the Regulation and of course in this process of implementation, we can also resolve some other problems of our companies, by making them more secure, more organized and more integrated in the modern world of economics.

\section{References}

European Parliament. (2016). Regulation (EU) 2016/679 of the European Parliament and of the Council of 27 April 2016 on the protection of natural persons with regard to the processing of personal data and on the free movement of such data, and repealing Directive 95/46/EC (General Da. Official Journal of the European Union, 59, 1-88. Retrieved from https://eur-lex.europa.eu/eli/reg/2016/679/oj

Information privacy law. (2019). Retrieved from https://en.wikipedia.org/wiki/Information_privacy_law

Malgieri, G., \& Custers, B. (2018). Pricing privacy - the right to know the value of your personal data. Computer Law and Security Review, 34(2), 289-303. https://doi.org/10.1016/j.clsr.2017.08.006

Pantlin, N., Wiseman, C., \& Everett, M. (2018). Supply chain arrangements: The ABC to GDPR compliance-A spotlight on emerging market practice in supplier contracts in light of the GDPR. Computer Law and Security Review, 34(4), 881-885. https://doi.org/10.1016/j.clsr.2018.06.009

Tankard, C. (2016). What the GDPR means for businesses. Network Security, 2016(6), 5-8. https://doi.org/10.1016/S1353-4858(16)30056-3

Tikkinen-Piri, C., Rohunen, A., \& Markkula, J. (2018). EU General Data Protection Regulation: Changes and implications for personal data collecting companies. Computer Law and Security Review, 34(1), 134-153. https://doi.org/10.1016/j.clsr.2017.05.015 